\title{
MRI Conditionality in Patients with Spinal Cord Stimulation Devices
}

\author{
Sebastian Rubino ${ }^{a}$ Adedamola Adepoju $^{a}$ Vignessh Kumar $^{a}$ b Julia Prusik ${ }^{a}$ b \\ Nathaniel Murphy ${ }^{a}$ Stephane Owusu-Sarpong ${ }^{a} \quad$ Julie G. Pilitsis ${ }^{a, b}$ \\ Departments of a Neurosurgery and ${ }^{b}$ Neuroscience and Experimental Therapeutics, Albany Medical College, \\ Albany, N.Y., USA
}

\section{Key Words}

Magnetic resonance imaging, safety $\cdot$ Spinal cord

stimulation $\cdot$ Implanted devices

\section{Abstract}

Background: Because of the commonality of diagnostic magnetic resonance imaging (MRI), MRI conditional technology has increased throughout the device industry. It is often difficult to be aware of MRI specifications for each device. Objectives: We provide a review of the clinical experience with MRI and spinal cord stimulation (SCS) devices and develop a general reference of current device/MRI specifications. Methods: We reviewed the available literature on the clinical experience with SCS devices and examined its specifications. Results: We developed a user-friendly table of the specific compatibility of SCS devices in the USA and the European Union, and examined the existing literature on the clinical experience with MRI and SCS devices. We share our experience with obtaining spine MRI with MRI conditional SCS leads. Conclusion: By describing SCS device specifications and reviewing the literature, we provide a guide to implanting and treating physicians on obtaining MRIs in patients who have SCS devices.

(c) 2016 S. Karger AG, Basel

\section{Background}

Spinal cord stimulation (SCS) devices are surgically implanted tools against difficult-to-treat pain states such as failed back surgery syndrome, complex regional pain syndrome, and other types of chronic pain [1]. Until very recently, SCS device manufacturers recommended abstaining from magnetic resonance imaging (MRI) in patients with implanted SCS devices, in order to avoid patient hazards or device malfunctioning [2].

MRI is considered the gold standard for extensive clinical evaluation and diagnosis of numerous disorders of the central nervous system, musculoskeletal system and cardiovascular system [3]. Thus, being unable to safely undergo MRI clinically disadvantages implanted device patients such as those who undergo SCS. In the past, SCS devices have frequently been explanted when clinical care necessitates an MRI [1]. Explantation is a significant event that requires a surgical procedure and, thus, imposes tremendous physical and economic burdens on patients.

The growing number of patients undergoing implantation of SCS devices made the need for MRI conditional systems more apparent [1]. Multiple studies have demon-

\section{KARGER}

E-Mail karger@karger.com

www.karger.com/sfn
Julie G. Pilitsis, MD, $\mathrm{PhD}$

AMC Neurosurgery Group

47 New Scotland Avenue, MC 10

Albany, NY 12208 (USA)

E-Mail pilitsj@mail.amc.edu 
Table 1. MRI conditionality of SCS devices

\begin{tabular}{|c|c|c|c|c|}
\hline Leads & Systems (IPG) & Scan permitted & Restrictions/programming & Considerations \\
\hline \multicolumn{5}{|l|}{ Medtronic SCS ${ }^{1}$} \\
\hline $\begin{array}{l}\text { Perc.: } 1 \times 8 \text { Vectris } \\
\text { SureScan }\end{array}$ & SureScan Models & $\begin{array}{l}\text { Full-body } 1.5 \text {-tesla } \\
\text { closed, horizontal } \\
\text { bore }\end{array}$ & $\begin{array}{l}30 \text { min active scan time; no extensions; } \\
\text { only Injex anchors } 97791,97792 ; \\
\text { stimulation on MRI mode SAR }<2.0 \\
\mathrm{~W} / \mathrm{kg} \text { for whole body and }<3.2 \mathrm{~W} / \mathrm{kg} \\
\text { for head }\end{array}$ & Specific MRI settings \\
\hline $\begin{array}{l}\text { Perc.: } 1 \times 8,1 \times 4 \text { pisces } \\
\text { quad } \\
\text { Paddles: specify } 5-6-5 \text {, } \\
2 \times 8,2 \times 4 \text {, Resume Models }\end{array}$ & $\begin{array}{l}\text { Restore, Prime, } \\
\text { Synergy, } \\
\text { Versitrel, Itrel4 } \\
\text { Models starting } \\
\text { with } 377 \text { or } 74\end{array}$ & $\begin{array}{l}\text { Head-only } 1.5 \text {-tesla } \\
\text { closed, horizontal } \\
\text { bore }\end{array}$ & $\begin{array}{l}\text { Must have all components out of head } \\
\text { coil; stimulation off SAR }<3.2 \mathrm{~W} / \mathrm{kg}\end{array}$ & $\begin{array}{l}\text { Titan } 3550-39 \text { /Injex 97791, 97792 } \\
\text { anchors and extensions 37081, 82, } \\
83 \text { can be used provided they are } \\
\text { not located by the calvarium; no } \\
\text { active scan time restrictions; } \\
\text { specific MRI settings }\end{array}$ \\
\hline Paddle: specify SureScan & SureScan Models & $\begin{array}{l}\text { Full-body } 1.5 \text {-tesla } \\
\text { closed, horizontal } \\
\text { bore }\end{array}$ & $\begin{array}{l}30 \text { min active scan time; patient should } \\
\text { not exceed } 30 \text { min of active scan time } \\
\text { within a } 90 \text {-min period; stimulation on } \\
\text { normal mode SAR }<2.0 \mathrm{~W} / \mathrm{kg} \text { for } \\
\text { whole body and }<3.2 \mathrm{~W} / \mathrm{kg} \text { for head }\end{array}$ & $\begin{array}{l}\text { Specific MRI settings; within a } \\
90 \text {-min window, there should be a } \\
\text { total of } 60 \text { min of nonscan time }\end{array}$ \\
\hline
\end{tabular}

St. Jude SCS ${ }^{2}$

Paddle: 3228 Penta

3771 Protégé Head/extremity-only

1.5-tesla closed,

Lamitrode horizontal bore
30 min active scan time; LE approved except hip; UE approved only for wrist; perc. lead tip must be between $\mathrm{T} 7$ and T12 vertebrae; maximum of 2 perc. leads can be implanted; must have all components out of head coil; no extensions; stimulation off

\section{Nevro SCS ${ }^{3}$ \\ Perc.: LEAD $10 \times 8-\mathrm{xxB}$}

Senza NIPG1000 Head/knee/ or NIPG1500 wrist-only 1.5/

3-tesla closed, horizontal bore
15 min active scan time; must have all components out of head coil; stimulation off
Must be positioned supine with arms at side; all lead anchors/port plug 1111 are MR compatible; specific MRI settings

\section{Boston Scientific ${ }^{4}$}

Perc.: Linear 30 and $50 \mathrm{~cm}$, Linear ST 30 and $50 \mathrm{~cm}$,

Linear 3-4 $50 \mathrm{~cm}$,

Linear $3-650 \mathrm{~cm}$

Paddle: Artisan $50 \mathrm{~cm}$,

Coveredge $3250 \mathrm{~cm}$,

Coveredge $\times 3250 \mathrm{~cm}$
Head-only 1.5-tesla closed, horizontal bore
Transmit and receive head coil only, stimulation off, wait 6 weeks before MRI, lead must be below T5 level
LEAD2008-xxB (extension), ACCK5xxx (lead anchor) and ACCK7000 (IPG port plug) MR compatible; specific MRI settings

Clik anchor and Med A adaptor are MRI compatible US-SAR $<3.2 \mathrm{~W} / \mathrm{kg}$ EU-SAR $<1.5 \mathrm{~W} / \mathrm{kg}$ No abandoned leads, and they must be connected to the IPG

Perc. = Percutaneous; IPG = internal pulse generator; SAR = specific absorption rate; LE = lower extremity; UE = upper extremity. Activa Models have received European Union (EU) approval for conditional full-body MRI; not currently full-body MRI compatible in the USA. ${ }^{1}$ Approved for use in the USA and EU. ${ }^{2}$ Approved only for the USA. ${ }^{3}$ Approved in the USA, EU and Australia. ${ }^{4}$ Approved in the USA and EU. All other models are not MRI compatible.

strated that under specific conditions, MRI can be safe with SCS devices $[4,5]$. Concerns regarding the impact of MRI on patient safety will continue to grow as more patients opt to undergo surgical treatment for alleviation of their chronic pain [6]. Nearly 28,000 SCS surgeries are performed annually worldwide, contributing to a rapidly increasing patient population with implanted SCS devices [7]. It has been shown that an estimated $82-84 \%$ of SCS patients are expected to require at least $1 \mathrm{MRI}$ within 5 years after implantation [8]. Though this issue has been hotly debated, the reality is that physicians caring for patients order MRIs as their definitive examination, and it remains difficult and time-consuming to convince patients that they do not need these diagnostic tests, even when the indications are 'soft'.

In light of the changing device capabilities, this article provides a general reference that can be useful for implanting and treating physicians of the specifications of SCS de- 
Table 2. Published clinical experience with MRI conditional and MRI nonconditional devices

\begin{tabular}{|c|c|c|c|c|c|}
\hline $\begin{array}{l}\text { First author } \\
\text { [Ref.], year }\end{array}$ & Device & Study & MRI & Patients & AEs \\
\hline $\begin{array}{l}\text { De Andres [9], } \\
2014\end{array}$ & $\begin{array}{l}2 \text { MRI conditional Vectris } \\
\text { Surescan leads in thoracic region } \\
\text { with Restore sensor IPG } \\
\text { (Medtronic); IPG location not } \\
\text { specified }\end{array}$ & Case study & $\begin{array}{l}\text { 1.5-tesla MRI thoracic and } \\
\text { lumbar spine } \\
\text { Sagittal } \mathrm{T}_{1}, \mathrm{~T}_{2} \text {, stir and axial } \\
\mathrm{T}_{2}\end{array}$ & 1 & None \\
\hline $\begin{array}{l}\text { Mutter [2], } \\
2013\end{array}$ & $\begin{array}{l}\text { Medtronic SCS leads in thoracic } \\
\text { region (not MRI conditional but } \\
\text { leads otherwise not specified) with } \\
\text { IPG (Prime Advances, Itrel 3, } \\
\text { Restore Ultra, Synergy) in buttocks } \\
\text { (IPG deactivated prior to MRI and } \\
\text { checked after MRI) }\end{array}$ & Prospective & $\begin{array}{l}\text { 1.5-tesla MRI spine; } \mathrm{SAR} \\
\text { restricted to }<0.74 \mathrm{~W} / \mathrm{kg} \\
\mathrm{T}_{2} \text { axial, coronal and sagittal; } \\
\mathrm{T}_{1} \text { sagittal }\end{array}$ & $\begin{array}{l}13 \text { with } \\
16 \text { MRIs }\end{array}$ & $\begin{array}{l}3 \text { patients with warmth at } \\
\text { electrodes and } 1 \text { with } \\
\text { intermittent LE tingling }\end{array}$ \\
\hline $\begin{array}{l}\text { Moens [12], } \\
2012\end{array}$ & $\begin{array}{l}\text { Medtronic } 565 \text { in thoracic region } \\
\text { externalized (no IPG) }\end{array}$ & $\begin{array}{l}\text { Prospective } \\
\text { safety study } \\
\text { with non-MRI } \\
\text { conditional } \\
\text { devices }\end{array}$ & $\begin{array}{l}\text { 1.5-tesla brain MRI }\left(\mathrm{T}_{1} \text { TFE }\right. \\
\text { M2D, } \mathrm{T}_{1} \text { TFE 3D, FFE EPI, } \\
\text { MS, IR TSE MS, fMRI), and } \\
\text { 3-tesla brain MRI ( } \mathrm{T}_{1} \text { TFE } \\
\text { 3D, FFE EPI, MS, SE EPI, } \\
\text { MS, PRESS, SV, IR TSE MS, } \\
\text { MRS, fMRI) }\end{array}$ & 40 patients & None \\
\hline $\begin{array}{l}\text { De Andres [11], } \\
2007\end{array}$ & $\begin{array}{l}1 \text { or } 2 \text { four-electrode leads in } \\
\text { cervical or lumbar region and an } \\
\text { Itrel III }{ }^{\circledR} \text { or Synergy }{ }^{\circledR} \text { (Medtronic } \\
\text { Inc., Minneapolis, Minn., USA) } \\
\text { IPG (location not specified); IPG } \\
\text { turned off at } 0 \text { V prior to MRI and } \\
\text { checked following MRI }\end{array}$ & $\begin{array}{l}\text { Prospective } \\
\text { safety study } \\
\text { with non-MRI } \\
\text { conditional } \\
\text { devices }\end{array}$ & $\begin{array}{l}1.5 \text {-tesla MRI, cervical, } \\
\text { thoracic, lumbar, brain } \\
\text { receiver coils for spine scans } \\
\text { and head transmit coil for } \\
\text { brain scans; SAR }<0.9 \mathrm{~W} / \mathrm{kg}\end{array}$ & 31 patients & $\begin{array}{l}2 \text { IPG malfunctions } \\
\text { necessitating surgical revision; } \\
5 \text { patients felt stimulation; } \\
2 \text { patients felt IPG warmth; } \\
4 \text { patients had programming } \\
\text { change; } 1 \text { patient had increased } \\
\text { impedances; } \\
1 \text { patient required decreased } \\
\text { amplitude after }\end{array}$ \\
\hline
\end{tabular}

AEs = Adverse events; SAR = specific absorption rate; LE = left extremity; IPG = internal pulse generator; TFE = turbo field echo; $\mathrm{M} 2 \mathrm{D}=$ multi-2-dimensional; $\mathrm{fMRI}=$ functional magnetic resonance imaging; $\mathrm{FFE}=$ fast field echo; $\mathrm{EPI}=$ echo planar imaging; $\mathrm{MS}=$ multislice; $\mathrm{SE}=\mathrm{spin}$ echo; $\mathrm{IR}=\mathrm{inversion}$ recovery; TSE = turbo spin echo; GE = gradient echo; MRS = magnetic resonance spectroscopy; PRESS = point resolved spectroscopy; SV = single voxel.

vices as well as a summary of the literature on its safety to date. By providing insight regarding the type of MRI appropriate for various systems, we aim to improve safety for patients with SCS devices who are undergoing MRI.

\section{Methods}

We first performed a literature search of 'SCS and MRI' in PubMed in English from 1992 to 2015 and located 4 articles which discuss the clinical experience with imaging in SCS. We then reviewed the available literature on SCS devices to create a comprehensive table, which specifies the devices with MRI conditionality and their restrictions of the available SCS devices. Since SCS MRI conditionality was approved in the USA just over the last 3 years, there is a limited published experience in this arena. Our article discusses 3 cases where we performed lumbar MRI with the MRI conditional devices.

\section{Results}

The MRI condition specifications for SCS devices in the USA and European Union are shown in table 1. In table 2, we describe the clinical experience of MRI with SCS. There are 4 reports in the literature -3 performed with non-MRI conditional devices with varying experiences seemingly dependent on whether there was an internal pulse generator or not and what the specific absorption rate was [9]. The latter is a dosimetric variable that represents the amount of radiofrequency power absorbed per unit of mass that is generally used to characterize the thermogenic properties of an electromagnetic field [10]. It is expressed in weight per kilogram. A letter to the editor is the only report of MRI with an MRI conditional SCS lead in place $[2,11,12]$. In our time of implanting MRI conditional leads, we have attempted to order 3 MRIs. The first patient unfortunately had a question of infection at the lead site; as 
Fig. 1. MRI of the sagittal lumbar spine (a) and the axial spine L1-2 (b).
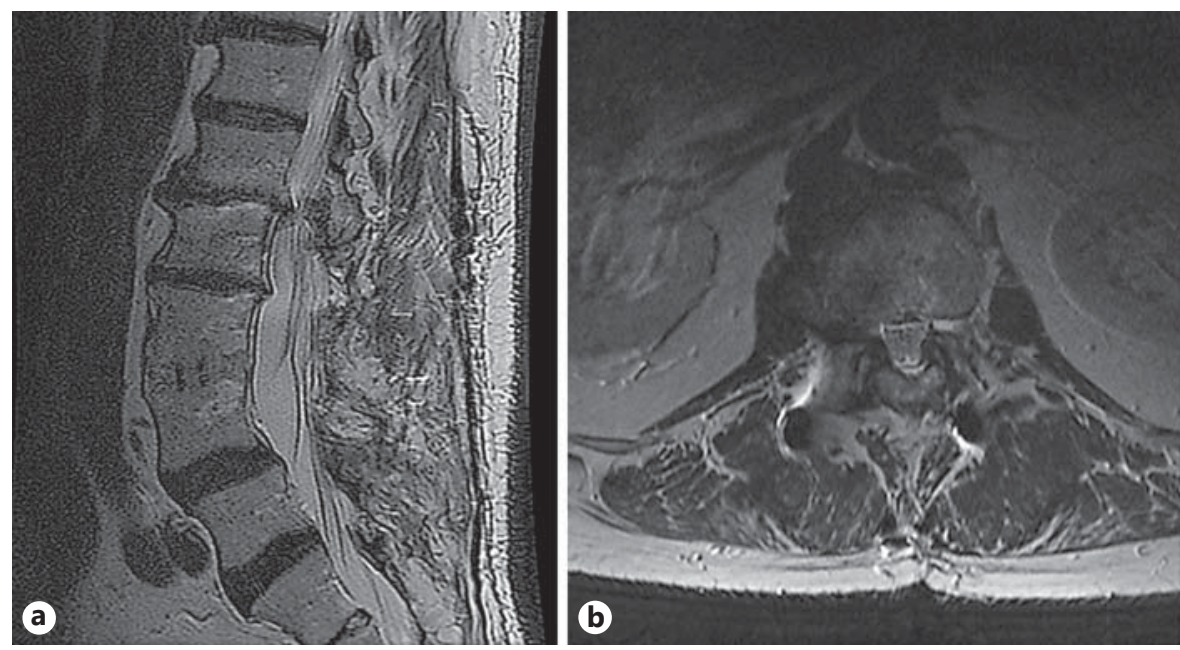

this is a contraindication to lumbar imaging, we were unable to obtain this imaging. The second patient was a 71-year-old male with failed back surgery syndrome. After a successful SCS trial, he was implanted with the percutaneous MRI conditional SCS. One year postoperatively, he had an acute exacerbation of chronic lower back pain with radicular complaints. He failed conservative therapy and ultimately underwent lumbar MRI, which showed a disk herniation causing foraminal stenosis at the level above his fusion (fig. 1). The third and final patient had new onset radicular symptoms 3 months following thoracic SCS. Despite vigorous education on initiating conservative therapy, this patient remained adamant regarding an MRI after 2 weeks of medical management and physical therapy. In light of the fact that epidural steroid injections were our next recommendation, we obtained the MRI.

There are 3 principal magnetic fields in MRI that may interact with surgically implanted systems: the static field, the radiofrequency field, and the pulsed gradient field [13]. The static magnetic field induces mechanical force and torque on ferromagnetic objects, such as those contained within SCS systems [13]. Pulsed gradient magnetic fields can induce voltages and currents on leads. Surgically implanted devices can concentrate these induced currents, which could result in electrical interference or even nerve stimulation. The radiofrequency magnetic field can also induce current into the body - this in turn can lead to dangerous heating of surrounding tissues (e.g. leads) [4, 13].

Innovations in SCS technology are aimed at resolving the two most common issues causing MRI incompatibility: (1) patient discomfort due to movement or heating of the device [5] and (2) image artifacts produced due to the implanted device [14]. Heating of the lead in SCS devices can be controlled by the modification of several factors, including impedance of the wire, diameter of the lead, and properties of surrounding insulation material [15]. Lead movement is less likely to occur if the patient is positioned such that the imaging coil is located distant to the implanted SCS device. Additionally, the establishment of a thermal dose limit is an integral step in the development and configuration of neuromodulation systems that are conditionally safe during MRI procedures [5].

\section{Conclusion}

In this study, we provide a user-friendly comprehensive table of specific compatibility of SCS devices in the USA and European Union. We also examine the existing literature on the clinical experience with MRI and SCS and provide data into our early experience with full body MRI conditionality. We hope for this investigation to serve as a general guide to MRI compatibility with SCS devices and a review of clinical experience including ours with SCS systems.

\section{Disclosure Statement}

Dr. Julie Pilitsis is a consultant for Medtronic, St. Jude and Boston Scientific and receives grant support from Medtronic, Boston Scientific, St. Jude and NIH 1R01CA166379. She is medical advisor for Centauri and has stock equity. All other authors have no conflict of interest or financial disclosures related directly to this paper. 


\section{References}

1 Moeschler SM, Sanders RA, Hooten M, Hoelzer BC: Spinal cord stimulator explantation for magnetic resonance imaging: a case series. Neuromodulation 2015;18:285-288.

2 Mutter UM, Bellut D, Porchet F, Schuknecht B: Spinal magnetic resonance imaging with reduced specific absorption rate in patients harbouring a spinal cord stimulation device - a single-centre prospective study analysing safety, tolerability and image quality. Acta Neurochir (Wien) 2013;155:2327-2332.

3 Kalin R, Stanton MS: Current clinical issues for MRI scanning of pacemaker and defibrillator patients. Pacing Clin Electrophysiol 2005;28:326-328.

4 Tronnier HT, Melchert U, Petersen D, Tronnier VM: Risk assessment of magnetic resonance imagining in chronically implanted paddle electrodes for cortical stimulation. Sterotact Func Neurosurg 2015;93:182-189.

5 Coffey RJ, Kalin R, Olsen JM: Magnetic resonance imaging conditionally safe neurostimulation leads: investigation of the maximum safe lead tip temperature. Neurosurgery 2014; 74:215-224.
6 Frey ME, Manchikanti L, Benyamin RM, Schultz DM, Smith HS, Cohen SP: Spinal cord stimulation for patients with failed back surgery syndrome: a systematic review. Pain Physician 2009;12:379-397.

7 Prager J: Estimates of annual spinal cord stimulator implant rises in the United States. Neuromodulation 2010;13:68-69.

8 Desai MJ, Hargens LM, Breitenfeldt MD, Doth AH, Ryan MP, Gunnarsson C, Safriel Y: The rate of magnetic resonance imaging in patients with spinal cord stimulation. Spine 2015;40:E531-E537.

9 De Andres J, Martinez-Sanjuan V, FabregatCid G, Asensio-Samper JM, Sanchis-Lopez N, et al: MRI-compatible spinal cord stimulator device and related changes in patient safety and imaging artifacts. Pain Med 2014;15: 1815-1819.

10 Angelone LM, Potthast A, Segonne F, Iwaki S, Belliveau JW, Bonmassar G: Metallic electrodes and leads in simultaneous EEG-MRI: specific absorption rate (SAR) stimulation studies. Bioelectromagnetics 2004;25:285295.
11 De Andres J, Valia JC, Cerda-Olmedo G, Quiroz C, Villanueva V, Martinez-Sanjuan V, de Leon-Casasola O: Magnetic resonance imaging in patients with spinal neurostimulation systems. Anesthesiology 2007;106:779786.

12 Moens M, Droogmans S, Spapen H, De Smedt A, Brouns R, et al: Feasibility of cerebral magnetic resonance imaging in patients with externalised spinal cord stimulator. Clin Neurol Neurosurg 2012;114:135-141.

13 Nyenhuis JA, Park S, Kamondetdacha R, Amjad A: MRI and implanted medical devices: basic interactions with an emphasis on heating. IEEE Trans Dev Mater Reliab 2005;5: 467-480.

14 Rampini PM, Locatelli M, Alimehmeti R, Tamma F, Caputo E, Priori A, Pesenti A, Rohr M, Egidi M: Multiple sequential image-fusion and direct MRI localisation of the subthalamic nucleus for deep brain stimulation. J Neurosurg Sci 2003;47:33-39.

15 McCabe SO, Scott JB: Cause and amelioration of MRI-induced heating through medical implant lead wires. 21st Electronics New Zealand Conference, Hamilton, November 2014. 